\title{
Papers
}

\section{Glycated haemoglobin, diabetes, and mortality in men in Norfolk cohort of European Prospective Investigation of Cancer and Nutrition (EPIC-Norfolk)}

\author{
Kay-Tee Khaw, Nicholas Wareham, Robert Luben, Sheila Bingham, Suzy Oakes, Ailsa Welch, \\ Nicholas Day
}

\begin{abstract}
Objective To examine the value of glycated haemoglobin $\left(\mathrm{HbA}_{1 \mathrm{c}}\right)$ concentration, a marker of blood glucose concentration, as a predictor of death from cardiovascular and all causes in men.

Design Prospective population study.

Setting Norfolk cohort of European Prospective Investigation into Cancer and Nutrition (EPIC-Norfolk).

Subjects 4662 men aged 45-79 years who had had glycated haemoglobin measured at the baseline survey in 1995-7 who were followed up to December 1999.
\end{abstract}

Main outcome measures Mortality from all causes, cardiovascular disease, ischaemic heart disease, and other causes.

Results Men with known diabetes had increased mortality from all causes, cardiovascular disease, and ischaemic disease (relative risks 2.2, 3.3, and 4.2, respectively, $\mathrm{P}<0.001$ independent of age and other risk factors) compared with men without known diabetes. The increased risk of death among men with diabetes was largely explained by $\mathrm{HbA}_{1 c}$ concentration. $\mathrm{HbA}_{1 c}$ was continuously related to subsequent all cause, cardiovascular, and ischaemic heart disease mortality through the whole population distribution, with lowest rates in those with $\mathrm{HbA}_{1 \mathrm{c}}$ concentrations below 5\%. An increase of $1 \%$ in $\mathrm{HbA}_{1 \mathrm{c}}$ was associated with a $28 \%(\mathrm{P}<0.002)$ increase in risk of death independent of age, blood pressure, serum cholesterol, body mass index, and cigarette smoking habit; this effect remained (relative risk 1.46, $\mathrm{P}=0.05$ adjusted for age and risk factors) after men with known diabetes, $\mathrm{a} \mathrm{HbA}_{1 \mathrm{c}}$ concentration $\geqslant 7 \%$, or history of myocardial infarction or stroke were excluded. $18 \%$ of the population excess mortality risk associated with a $\mathrm{HbA}_{1 \mathrm{c}}$ concentration $\geqslant 5 \%$ occurred in men with diabetes, but $82 \%$ occurred in men with concentrations of 5\%-6.9\% (the majority of the population).

Conclusions Glycated haemoglobin concentration seems to explain most of the excess mortality risk of diabetes in men and to be a continuous risk factor through the whole population distribution. Preventive efforts need to consider not just those with established diabetes but whether it is possible to reduce the population distribution of $\mathrm{HbA}_{1 \mathrm{c}}$ through behavioural means.

\section{Introduction}

The global prevalence of diabetes is predicted to rise from 135 million in 1995 to 300 million by $2025 .^{1-3} \mathrm{In}$ the United Kingdom, diabetes and associated complications cost the NHS $£ 4.9 \mathrm{bn}$ a year, about a tenth of its entire budget.

Various blood glucose threshold concentrations have been proposed for the diagnosis of diabetes, ${ }^{4-7}$ based on the relation to risk of microvascular complications of diabetes, particularly retinopathy. ${ }^{8}$ However, people with diabetes are also at increased risk of macrovascular diseases such as coronary heart disease and stroke, ${ }^{9}$ and it is uncertain whether the relation between blood glucose concentration and such diseases has a threshold or is a continuum.

Glycated haemoglobin $\left(\mathrm{HbA}_{1 c}\right)$ concentration is an indicator of average blood glucose concentration over three months and has been suggested as a diagnostic or screening tool for diabetes. ${ }^{810}$ Meta-regression analyses of several studies suggest a continuous relation between fasting or two hour glucose concentration and macrovascular events even below accepted thresholds for diabetes, but data for glycated haemoglobin have been limited by the few prospective studies in which it has been measured in people without diabetes.

We examined the relation between glycated haemoglobin concentrations, diabetes, and subsequent mortality in men.

\section{Participants and methods}

We studied men in the Norfolk cohort of the European Prospective Investigation into Cancer and Nutrition. The cohort comprises 25623 men and women aged 45-79 years resident in Norfolk, recruited from general practice age-sex registers. ${ }^{11}$ Additional data were collected for the Norfolk cohort to enable us to examine the determinants of chronic disease. At the baseline survey between 1993 and 1997

\author{
Department of \\ Public Health and \\ Primary Care, \\ Institute of Public \\ Health, University \\ of Cambridge \\ School of Clinical \\ Medicine, \\ Cambridge \\ CB2 2SR \\ Kay-Tee Khaw \\ professor of clinical \\ gerontology \\ Nicholas Wareham \\ Medical Research \\ Council clinician \\ scientist \\ Robert Luben \\ research associate, \\ computing and \\ biostatistics \\ Suzy Oakes \\ research associate \\ Ailsa Welch \\ research associate, \\ nutrition \\ Nicholas Day \\ Medical Research \\ Council research \\ professor \\ Medical Research \\ Council Dunn \\ Human Nutrition \\ Unit, Cambridge \\ CB2 2XY \\ Sheila Bingham \\ deputy director \\ Correspondence to: \\ K-T Khaw, Clinical \\ Gerontology Unit, \\ Box 251, University \\ of Cambridge \\ School of Clinical \\ Medicine, \\ Addenbrooke's \\ Hospital, \\ Cambridge \\ CB2 2QQ \\ kk101@medschl. \\ cam.ac.uk
}

BMJ 2001;322:1-6 
participants completed a detailed health and lifestyle questionnaire. People with established diabetes were defined as those who responded "yes" to the diabetes option of the question: "Has a doctor ever told you that you have any of the following?" followed by a list of conditions including diabetes, heart attack, and stroke. Smoking history was derived from responses to the questions "Have you ever smoked as much as one cigarette a day for as long as a year?" and "Do you smoke cigarettes now?"

Participants attended a health examination carried out by trained nurses. Body mass index was estimated as weight $(\mathrm{kg}) /(\text { height }(\mathrm{m}))^{2}$. Blood pressure was measured with an Accutorr blood pressure monitor ${ }^{12}$ after the participant had been seated resting for five minutes; the mean of two readings was used for analysis. Plasma and serum samples were obtained from blood taken by venepuncture. From November 1995, an additional EDTA-anticoagulated blood sample was taken for measurement of $\mathrm{HbA}_{1 c}$. Blood samples were assayed at the department of clinical biochemistry, Cambridge University. Serum total cholesterol, high density lipoprotein cholesterol, and triglyceride concentrations were measured by colorimetry (RA 1000, Bayer Diagnostics, Basingstoke), and low density lipoprotein cholesterol concentrations were calculated by the Friedewald formula. ${ }^{13}$ Glycated haemoglobin assays used a Biorad Diomat high pressure liquid chromatography analyser. The coefficient of variation was $3.6 \%$.

All participants were flagged for death certification at the Office of National Statistics. We present results for mortality follow up to December 1999. Death certificates were coded by trained nosologists at the Office of National Statistics according to the International Classification of Disease (ICD), 9th revision. Cardiovascular death was defined as ICD 400-438 and ischaemic heart disease death as ICD 410-414 anywhere on the death certificate.

The study was approved by the Norwich District Health Authority ethics committee, and all participants gave signed informed consent.

The analysis reported here includes all men aged 45-79 years who completed the baseline health examination and had $\mathrm{HbA}_{1 c}$ measured. There were not enough events in women with $\mathrm{HbA}_{1 c}$ measurements for robust analyses. We divided the men into five categories: those with established diabetes, those with previously undiagnosed diabetes (defined as those without a history of diabetes but with a $\mathrm{HbA}_{1 c}$ concentration $\geqslant 7 \% 0^{8}$ ), and then the remainder by approximate thirds of $\mathrm{HbA}_{1 \mathrm{c}}$ concentration using clinically applicable cut off points. We calculated age adjusted death rates by cause in these categories using $\chi^{2}$ for linear trend to assess statistical significance. ${ }^{14}$ We used the Cox proportional hazards model to determine the contribution of risk factors to mortality. ${ }^{15}$

We also calculated the population distribution of $\mathrm{HbA}_{\mathrm{lc}}$ concentration and diabetes and estimated the population attributable risk associated with diabetes or $\mathrm{HbA}_{1 \mathrm{c}}$ above the lowest category less than $5 \%$, assuming the death rates for those with $\mathrm{a} \mathrm{HbA}_{1 c}$ concentration less than $5 \%$ applied to the whole population.

\section{Results}

Table 1 shows the characteristics of the 4662 men according to concentration of $\mathrm{HbA}_{1 \mathrm{c}}$ and self reported diabetes. Men with self reported diabetes or previously undiagnosed diabetes were older and had higher levels of risk factors for cardiovascular disease than the rest of the population.

Table 2 shows age adjusted mortality by concentration of $\mathrm{HbA}_{1 \mathrm{c}}$ and self reported diabetes. Men with established or undiagnosed diabetes had greater risk of dying from all causes, cardiovascular disease, or ischaemic heart disease compared with men without diabetes. Risk of death increased through the range of $\mathrm{HbA}_{1 \mathrm{c}}$ concentrations, with lowest rates in those with $\mathrm{HbA}_{1 \mathrm{c}}$ concentrations less than $5 \%$ and a gradient of increasing rates through the whole distribution.

Table 3 shows the independent multivariate relation between $\mathrm{HbA}_{1 \mathrm{c}}$ concentration or diabetes status and mortality with the Cox proportional hazards model after adjustment for age alone and for age, systolic blood pressure, serum cholesterol concentration, body mass index, cigarette smoking habit, and history of myocardial infarction or stroke. In separate models diabetes status significantly predicted death from all causes, cardiovascular disease, and ischaemic heart disease and $\mathrm{HbA}_{1 \mathrm{c}}$ concentrations predicted all cause, cardiovascular, ischaemic heart disease, and

Table 1 Characteristics of study population by concentration of glycated haemoglobin and self reported diabetes. Values are mean (SD) unless stated otherwise

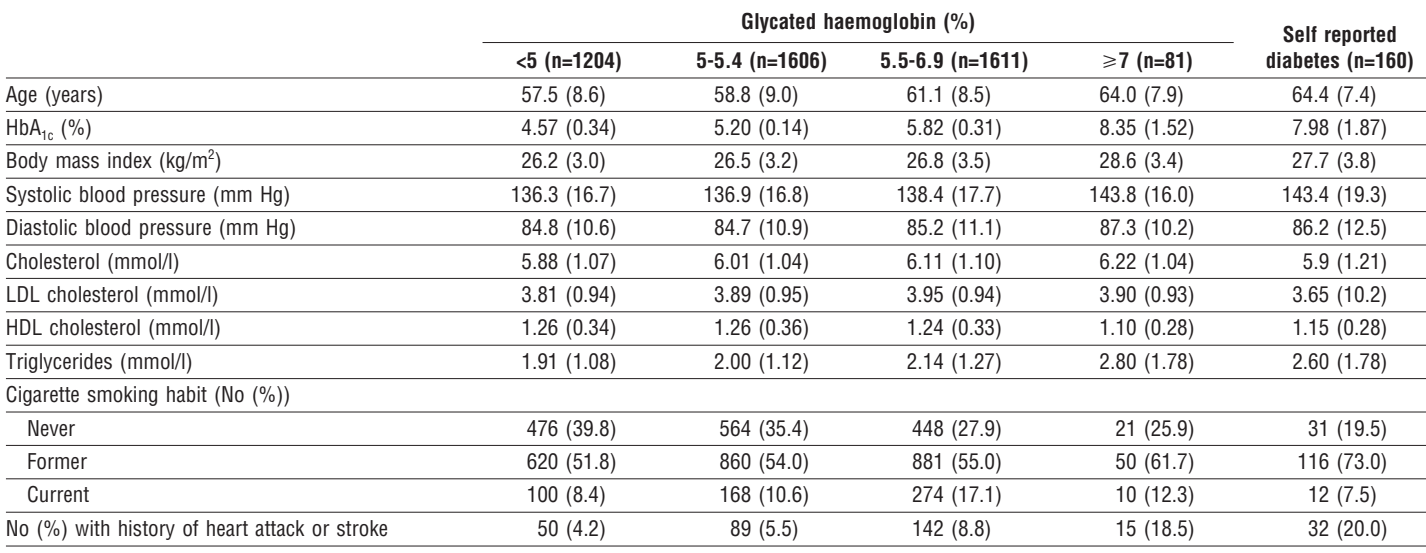

$\mathrm{P}<0.001$ for differences between categories for all variables except diastolic blood pressure. 
Table 2 Age adjusted rates for all cause, cardiovascular, ischaemic heart disease, and non-cardiovascular death by glycated haemoglobin concentration and self reported diabetes in men aged 45-79 years, 1995-9

\begin{tabular}{|c|c|c|c|c|c|c|}
\hline \multirow[b]{2}{*}{ Cause of death } & \multicolumn{4}{|c|}{ Glycated haemoglobin (\%) } & \multirow{2}{*}{$\begin{array}{l}\text { Self reported } \\
\text { diabetes } \\
(n=160)\end{array}$} & \multirow[b]{2}{*}{$\begin{array}{c}\chi^{2} \text { (linear trend) } \\
\text { P value }\end{array}$} \\
\hline & $\begin{array}{c}<5 \\
(n=1204)\end{array}$ & $\begin{array}{c}5-5.4 \\
(n=1606)\end{array}$ & $\begin{array}{c}5.5-6.9 \\
(n=1611)\end{array}$ & $\begin{array}{c}\geqslant 7 \\
(n=81)\end{array}$ & & \\
\hline \multicolumn{7}{|l|}{ All causes $(n=135)$} \\
\hline Age adjusted rate/100 (No of events) & $1.65(18)$ & $2.33(35)$ & $3.43(61)$ & $4.35(5)$ & $5.92(16)$ & 40.8, \\
\hline Relative risk & 1.00 & 1.41 & 2.07 & 2.64 & 3.59 & $<0.001$ \\
\hline \multicolumn{7}{|l|}{ Cardiovascular disease $(n=60)$} \\
\hline Age adjusted rate/100 (No of events) & $0.50(5)$ & $1.27(19)$ & $1.24(22)$ & $2.54(3)$ & $4.11(11)$ & 31.8 \\
\hline Relative risk & 1.00 & 2.53 & 2.46 & 5.04 & 8.16 & $<0.001$ \\
\hline \multicolumn{7}{|l|}{ Ischaemic heart disease $(n=42)$} \\
\hline Age adjusted rate/100 (No of events) & $0.31(3)$ & $0.86(13)$ & $0.87(15)$ & $1.63(2)$ & $3.43(9)$ & 29.0 \\
\hline Relative risk & 1.00 & 2.74 & 2.77 & 5.20 & 10.91 & $<0.001$ \\
\hline \multicolumn{7}{|l|}{ Non-cardiovascular disease $(\mathrm{n}=75)$} \\
\hline Age adjusted rate/100 (No of events) & $1.15(13)$ & $1.06(16)$ & $2.19(39)$ & $1.81(2)$ & $1.82(5)$ & 11.8, \\
\hline Relative risk & 1.00 & 0.92 & 1.91 & 1.58 & 1.58 & $<0.001$ \\
\hline
\end{tabular}

non-cardiovascular mortality independently of age and known risk factors. When diabetes status and $\mathrm{HbA}_{1 \mathrm{c}}$ concentration were both included in the same model, diabetes no longer significantly independently predicted mortality. The increased risk of mortality in men with diabetes was largely mediated through $\mathrm{HbA}_{1 c}$ concentration. An increase of $1 \%$ in $\mathrm{HbA}_{1 c}$ concentration was associated with roughly a $30 \%$ increase in all cause and $40 \%$ increase in cardiovascular or ischaemic heart disease mortality. After men with a history of diabetes or with a $\mathrm{HbA}_{1 \mathrm{c}}$ concentration $\geqslant 7 \%$ and those with a history of heart disease and stroke $(n=522)$ were excluded, the relative risk of all cause mortality for a $1 \%$ increase in $\mathrm{HbA}_{1 \mathrm{c}}$ was 1.49 (95\% confidence interval 1.03 to $2.17, \mathrm{P}=0.03$ ) adjusted for age and 1.46 (1.00 to $2.12, \mathrm{P}=0.05$ ) adjusted for age and risk factors.

Table 4 shows the distribution of $\mathrm{HbA}_{1 c}$ concentration and self reported diabetes in these men. It also shows the population attributable risk, an estimate of the excess mortality associated with diabetes or $\mathrm{HbA}_{1 c}$ concentration $\geqslant 5 \%$. About $37 \%(48 / 131)$ of the total deaths in this population could be attributed to excess mortality in men with $\mathrm{HbA}_{1 \mathrm{c}}$ concentrations $\geqslant 5 \%$. The prevalence of established or newly diagnosed diabetes was about $5 \%$ in the study population. Although this group had greatly increased relative risk of mortality, they contributed only $18 \%$ of the excess deaths from all causes relating to $\mathrm{HbA}_{1 \mathrm{c}}>5 \%$; men with $\mathrm{HbA}_{1 \mathrm{c}}$ concentrations of $5 \%-6.9 \%$, who form the majority of the population, contributed about $82 \%$ of the excess mortality. Table 4 also shows the estimated effect on prevalence distributions if $\mathrm{HbA}_{1 \mathrm{c}}$ concentrations were lowered by $0.1 \%$ or $0.2 \%$ in everyone in the population (excluding those with self reported diabetes). An estimated 12\% (6/48) of the excess deaths could potentially be prevented by lowering the population mean $\mathrm{HbA}_{1 \mathrm{c}}$ concentration by $0.1 \%$, and $25 \%(13 / 48)$ could be prevented by lowering the population mean by $0.2 \%$. The reduction in total deaths would be $5 \%(6 / 131)$ and $10 \%(13 / 131)$ respectively.

Table 3 Cox multivariate regression for 4662 men aged 45-79 years for all cause, cardiovascular, ischaemic heart disease, and non-cardiovascular mortality, 1995-9. Effects of glycated haemoglobin and diabetes status were modelled separately (models 1 and 2) and together (model 3)

\begin{tabular}{|c|c|c|c|c|c|}
\hline \multicolumn{2}{|c|}{ Cause of death } & $\begin{array}{l}\text { Relative risk adjusted for age } \\
(95 \% \mathrm{CI})\end{array}$ & $P$ value & $\begin{array}{l}\text { Relative risk adjusted for age and } \\
\text { risk factors* }(95 \% \mathrm{Cl})\end{array}$ & $P$ value \\
\hline \multicolumn{6}{|c|}{ All causes (131 events†) } \\
\hline Model 1 & $\mathrm{HbA}_{1 \mathrm{c}}$ (per 1\% increase) & 1.32 (1.18 to 1.47$)$ & 0.0001 & 1.29 (1.14 to 1.45$)$ & 0.0001 \\
\hline Model 2 & Diabetes history (yes $v$ no) & 2.56 (1.49 to 4.40$)$ & 0.0006 & 2.15 (1.23 to 3.77$)$ & 0.007 \\
\hline \multirow[t]{2}{*}{ Model 3} & $\mathrm{HbA}_{1 \mathrm{c}}$ (per $1 \%$ increase) & 1.27 (1.10 to 1.47$)$ & 0.001 & 1.28 (1.09 to 1.49$)$ & 0.002 \\
\hline & Diabetes history (yes $v$ no) & 1.33 (0.66 to 2.67$)$ & 0.42 & 1.08 (0.52 to 2.25$)$ & 0.83 \\
\hline \multicolumn{6}{|c|}{ Cardiovascular disease (60 events) } \\
\hline Model 1 & $\mathrm{HbA}_{1 \mathrm{c}}$ (per $1 \%$ increase) & 1.41 (1.21 to 1.64$)$ & 0.0001 & 1.38 (1.18 to 1.61$)$ & 0.001 \\
\hline Model 2 & Diabetes history (yes $v$ no) & 3.91 (1.97 to 7.73 ) & 0.0001 & 3.31 (1.61 to 6.8$)$ & 0.001 \\
\hline \multirow[t]{2}{*}{ Model 3} & $\mathrm{HbA}_{1 \mathrm{c}}$ (per $1 \%$ increase) & 1.29 (1.05 to 1.59$)$ & 0.01 & 1.29 (1.05 to 1.60$)$ & 0.01 \\
\hline & Diabetes history (yes $v$ no) & 1.96 (0.78 to 4.90$)$ & 0.15 & 1.63 (0.62 to 4.23$)$ & 0.32 \\
\hline \multicolumn{6}{|c|}{ Ischaemic heart disease (41 events $†$ ) } \\
\hline Model 1 & $\mathrm{HbA}_{1 \mathrm{c}}$ (per $1 \%$ increase) & $1.51(1.29$ to 1.77$)$ & 0.0001 & $1.44(1.21$ to 1.71$)$ & 0.0001 \\
\hline Model 2 & Diabetes history (yes $v$ no) & 4.85 (2.23 to 10.55$)$ & 0.0001 & 4.24 (1.92 to 9.35$)$ & 0.0003 \\
\hline \multirow[t]{2}{*}{ Model 3} & $\mathrm{HbA}_{1 \mathrm{c}}$ (per $1 \%$ increase) & $1.40(1.12$ to 1.74$)$ & 0.003 & 1.31 (1.02 to 1.67$)$ & 0.03 \\
\hline & Diabetes history (yes $v$ no) & 1.90 (0.67 to 5.37$)$ & 0.22 & 2.69 (1.34 to 5.43$)$ & 0.21 \\
\hline \multicolumn{6}{|c|}{ Non-cardiovascular causes (75 events) } \\
\hline Model 1 & $\mathrm{HbA}_{1 \mathrm{c}}$ (per $1 \%$ increase) & $1.23(1.04$ to 1.46$)$ & 0.02 & 1.20 (1.01 to 1.44$)$ & 0.04 \\
\hline Model 2 & Diabetes history (yes $v$ no) & 1.52 (0.61 to 3.80$)$ & 0.36 & 1.34 (0.54 to 3.36$)$ & 0.52 \\
\hline \multirow[t]{2}{*}{ Model 3} & $\mathrm{HbA}_{1 \mathrm{c}}$ (per $1 \%$ increase $)$ & 1.26 (1.02 to 1.55$)$ & 0.03 & 1.26 (1.01 to 1.59$)$ & 0.04 \\
\hline & Diabetes history (yes $v$ no) & $0.80(0.26$ to 2.44$)$ & 0.70 & $0.70(0.22$ to 1.59$)$ & 0.54 \\
\hline
\end{tabular}

${ }^{\star}$ Risk factors are systolic blood pressure, serum cholesterol concentration, body mass index, cigarette smoking, and history of myocardial infarction or stroke. †Some data were missing for multivariate analysis. 
Table 4 Prevalence of self reported diabetes and glycated haemoglobin concentration and percentage population excess mortality associated with glycated haemoglobin $5 \%$ or higher in men 45-79 years, $1995-9$

\begin{tabular}{|c|c|c|c|c|c|}
\hline & \multicolumn{4}{|c|}{ Glycated haemoglobin (\%) } & \multirow{2}{*}{$\begin{array}{c}\text { Self } \\
\text { reported } \\
\text { diabetes } \\
(\mathrm{n}=160)\end{array}$} \\
\hline & $\begin{array}{c}<5 \\
(n=1204)\end{array}$ & $\begin{array}{c}5-5.4 \\
(n=1606)\end{array}$ & $\begin{array}{c}5.5-6.9 \\
(n=1611)\end{array}$ & $\begin{array}{c}\geqslant 7 \\
(n=81)\end{array}$ & \\
\hline Prevalence in study population (\%) & 25.8 & 34.4 & 34.6 & 1.7 & 3.4 \\
\hline \multicolumn{6}{|l|}{$\%$ contribution to excess mortality from } \\
\hline All causes & - & 23 & 59 & 4 & 14 \\
\hline Cardiovascular disease & - & 39 & 38 & 5 & 18 \\
\hline Ischaemic heart disease & - & 37 & 38 & 4 & 21 \\
\hline $\begin{array}{l}\text { Prevalence if population mean lowered by } \\
0.1 \% \mathrm{HbA}_{1 \mathrm{c}}(\%)\end{array}$ & 32.4 & 34.8 & 27.7 & 1.6 & 3.4 \\
\hline $\begin{array}{l}\text { Prevalence if population mean lowered by } \\
0.2 \% \mathrm{HbA}_{1 \mathrm{c}}(\%)\end{array}$ & 38.5 & 38.8 & 17.7 & 1.5 & 3.4 \\
\hline
\end{tabular}

\section{Discussion}

Glycated haemoglobin concentration significantly predicted mortality, with increasing risk throughout the whole range of concentrations, even below the threshold commonly accepted for diagnosis of diabetes. This effect was independent of known risk factors and consistent after men with existing diabetes, heart disease, and stroke were excluded. The predictive value of $\mathrm{HbA}_{1 \mathrm{c}}$ for total mortality was stronger than that documented for cholesterol concentration, body mass index, and blood pressure. The mortality risk of established diabetes seemed to be mediated largely through $\mathrm{HbA}_{1 \mathrm{c}}$ concentration.

People with diabetes have increased risk of vascular disease, ${ }^{9}{ }^{16-18}$ and in these people blood concentration of glucose or $\mathrm{HbA}_{1 \mathrm{c}}$ predicts subsequent microvascular and macrovascular events. ${ }^{19}{ }^{20}$ High glucose concentrations might accelerate atherosclerotic processes through several plausible mechanisms such as oxidative stress and protein glycation of vessel walls. ${ }^{21}$ Reductions in blood glucose or $\mathrm{HbA}_{1 \mathrm{c}}$ concentrations through tight blood glucose control in people with diabetes also reduces the risk of microvascular disease. ${ }^{22-25}$ However, whether the relation of increasing blood glucose with adverse clinical outcomes exists only above a threshold or is a continuous relation across the whole population distribution is still debated..$^{26-32}$ For microvascular complications, studies report a flat relation below a threshold for fasting and post challenge glucose concentration as well as for $\mathrm{HbA}_{1 \mathrm{c}}{ }^{8}$ The relation with macrovascular outcomes, coronary heart disease, and stroke, is less clear. ${ }^{26-32} \mathrm{~A}$ review $^{33}$ and meta-regression analysis of 20 prospective studies $^{34}$ (94\% male) concluded that the progressive relation between glucose concentrations and cardiovascular disease extends below the diabetic threshold.

\section{Importance of glycated haemoglobin in people without diabetes}

$\mathrm{HbA}_{\mathrm{lc}}$ concentration is related to prevalent coronary disease or carotid intimal thickening in non-diabetic people. ${ }^{35} 36$ Two prospective studies reported that $\mathrm{HbA}_{1 c}$ predicts cardiovascular disease in non-diabetic people, but they focused on the top end of the distribution, which may contain people with undiagnosed diabetes. ${ }^{37}{ }^{38}$ In the Norfolk cohort, the effect of $\mathrm{HbA}_{1 \mathrm{c}}$ concentration on mortality was evident even at the lower end of the population distribution, and there was no apparent threshold effect: men with $\mathrm{HbA}_{1 \mathrm{c}}$ concen- trations above $5 \%$ had greater risk than men with concentrations below 5\%. Glycated haemoglobin seems to resemble blood pressure and blood cholesterol in terms of the continuous relation with cardiovascular risk. ${ }^{39}$

\section{Clinical implications}

Clinical attention has focused on microvascular complications of diabetes. However, rates of myocardial infarction and stroke in diabetic people are about twice the rates of microvascular events, ${ }^{40}$ and control of other cardiovascular risk factors such as hypertension is particularly beneficial. ${ }^{41}$ Treatment trials have shown the effectiveness of lowering blood pressure and cholesterol concentration in reducing cardiovascular events. Since blood pressure and cholesterol are continuously related to mortality, ${ }^{39}$ prevention of cardiovascular disease has moved from single risk factor intervention at fixed thresholds to identifying overall cardiovascular risk in individuals. Lower treatment thresholds are recommended for people at high absolute risk, as estimated by age, sex, and cardiovascular risk factors such as diabetes, blood pressure, blood cholesterol, smoking, and family history. ${ }^{42}{ }^{43}$ Our data indicate that raised glycated haemoglobin concentration, even in men without diabetes, is a marker of greater absolute risk, and preventive treatment with blood pressure or cholesterol lowering drugs should be considered in such patients.

A diagnostic classification for diabetes based on fasting glucose concentration has been challenged by studies that show that glucose concentration two hours after a glucose load has greater predictive value for mortality. ${ }^{44-46}$ However, glucose loading is unsuitable for repeated monitoring. Detection and monitoring of hyperglycaemia would be enhanced by a test such as glycated haemoglobin.

\section{Public health implications}

Concentrations of glycated haemoglobin are roughly normally distributed in the population. The lowest death rates were in men with $\mathrm{HbA}_{1 \mathrm{c}}$ concentrations below $5 \%$ (25\% of our population). Established diabetes is associated with increased mortality, but the prevalence of diabetes is low (5\% in the population), whereas about $70 \%$ of the population have $\mathrm{HbA}_{1 \mathrm{c}}$ concentrations between $5 \%$ and $6.9 \%$. As table 4 shows, $82 \%$ of the population excess mortality occurred in this large group of the population compared with 18\% in those with diabetes. Large numbers of people exposed to a small increase in risk contribute more events to the population than a small number of people exposed to a large increase in risk. ${ }^{47}$ The intensive individual medical management and tight glucose control that has been achieved in treatment trials for diabetic patients would not be feasible, or necessarily beneficial, in people who do not have diabetes. However, if it were possible to lower the population mean distribution of $\mathrm{HbA}_{1 \mathrm{c}}$ concentration by lifestyle means such as diet or physical activity, many people could shift into lower risk categories. As shown in table 4 , after men with diabetes are excluded, a reduction of just $0.1 \% \mathrm{HbA}_{1 \mathrm{c}}$ in the whole population would reduce the prevalence of men with concentrations of $5 \%-6.9 \%$ from $79 \%$ to $63 \%$, and a population reduction of $0.2 \%$ $\mathrm{HbA}_{1 \mathrm{c}}$ would reduce the prevalence to $57 \%$. If the same 


\section{What is already known on this topic}

Diabetes mellitus increases cardiovascular disease risk

$\mathrm{HbA}_{1 \mathrm{c}}$ concentrations predict cardiovascular risk in people with diabetes

\section{What this study adds}

$\mathrm{HbA}_{1 c}$ concentrations predict mortality continuously across the whole population distribution in people without diabetes and at concentrations below those used to diagnose diabetes

People with high $\mathrm{HbA}_{1 \mathrm{c}}$ concentration may benefit from control of blood pressure and cholesterol concentration

$\mathrm{HbA}_{1 \mathrm{c}}$ may provide a practical screening tool for diabetes or impaired glucose tolerance

Over $80 \%$ of the population excess mortality associated with $\mathrm{HbA}_{1 \mathrm{c}}$ concentrations above 5\% occurred in $70 \%$ of the population with $\mathrm{HbA}_{1 \mathrm{c}}$ concentrations of $5 \%-6.9 \%$

death rates are assumed to apply, these reductions in population prevalence would reduce total mortality by $5 \%$ and $10 \%$ respectively.

Whether it is possible to shift the whole population distribution of glycated haemoglobin concentration is unknown. However, huge secular trends and migrant studies showing rapidly increasing prevalence of diabetes suggest that glucose tolerance in the population is susceptible to environmental changes and may be viewed as a societal problem. Studies have implicated nutrition and physical activity as important determinants of diabetes and glycaemia in populations. $^{48}{ }^{49}$ The challenge is to identify how much risk can be affected by small changes in the determinants of glycaemia at the population level and to devise strategies for bringing about these changes. ${ }^{50-52}$

We thank the participants and general practitioners who took part in EPIC-Norfolk.

Contributors: K-TK, ND, and SB originated and designed the EPIC-Norfolk population study. NW introduced the glycated haemoglobin measurements and diabetes component. SO is study coordinator and organised data collection including quality control of blood samples and measurement procedures. AW contributed to data collection and analysis. RL was responsible for data management and computing and assisted with analyses. $\mathrm{K}-\mathrm{TK}$ conducted the data analyses and wrote the paper with NW and ND. K-TK is guarantor for this paper.

Funding: EPIC-Norfolk is supported by programme grants from the Cancer Research Campaign and Medical Research Council with additional support from the Stroke Association, British Heart Foundation, Department of Health, and the Wellcome Trust.

Competing interests: None declared.

1 King H, Aubert RE, Herman WH. Global burden of diabetes, 1995-2025: prevalence, numerical estimates, and projections. Diabetes Care 1998;21:1414-31.

2 Amos AF, McCarty DJ, Zimmet P. The rising global burden of diabetes and its complications: estimates and projections to the year 2010. Diabet Med 1997;14(suppl 5):S1-85.

3 American Diabetes Association. Screening for type 2 diabetes. Diabetes Care 2000;23(suppl 1);S20-3.

4 National Diabetes Data Group. Classification and diagnosis of diabetes mellitus and other categories of glucose intolerance. Diabetes 1979;28:1039-57.
5 Report of a WHO Study Group. Diabetes mellitus. World Health Org Tech Rep Ser 1985;727:9-17

6 Alberti KG, Zimmet PZ. Definition, diagnosis and classification of diabetes mellitus and its complications. Part 1: diagnosis and classification of diabetes mellitus provision report of a WHO consultation. Diabet Med 1998;15:539-53

7 Report of the expert committee on the diagnosis and classification of diabetes mellitus. Diabetes Care 1997;20:1183-97.

8 McCance DR, Hanson RL, Charles M-A, Jacobsson LTH, Pettitt DJ, Bennett PH, et al. Comparison of tests for glycated hemoglobin and fasting and two hour plasma glucose concentrations as diagnostic methods for diabetes. BMJ 1994;308:1323-8.

9 Haffner SM, Lehto S, Ronnemaa T, Pyorala K, Lakkso M. Mortality from coronary heart disease in subjects with type 2 diabetes and in nondiabetic subjects with and without prior myocardial infarction. $N$ Engl J Med 1998;339:229-34

10 Marshall SM, Barth JH. Standardization of $\mathrm{HbA}_{1 \mathrm{c}}$ measurements - a consensus statement. Diabet Med 2000;17:5-6.

11 Day NE, Oakes S, Luben R, Khaw KT, Bingham S, Welch A, et al EPIC-Norfolk: study design and characteristics of the cohort. Br J Cancer 1999;80(suppl 1):95-103.

12 Gregory J, Foster K, Tyler H, Wiseman M. The dietary and nutritional surve) of British adults. London: HMSO: 1990 .

13 Friedewald WT, Levy RI, Frederickson DS. Estimation of the concentration of low-density lipoprotein cholesterol in plasma, without the use of the preparative ultracentrifuge. Clin Chem 1972;18:499-502.

14 Mantel N, Haenszel W. Statistical aspects of the analysis of data from retrospective studies of disease.J Natl Cancer Inst 1959:22:719-48.

15 Cox DR. Regression models and life tables. J R Stat Soc B 1972;34: $187-220$.

16 Kannel WB, McGee DL. Diabetes and glucose tolerance as risk factors for cardiovascular disease: the Framingham Study. Diabetes Care 1979;2:120-6.

17 Stamler J, Vaccaro O, Neaton JD, Wentworth D. Diabetes, other risk factors and 12 year cardiovascular mortality for men screened in the multiple risk factor intervention trial. Diabetes Care 1993;16:434-44.

18 Wingard DL, Barrett-Connor E. Heart disease and diabetes. In: National Diabetes Data Group. Diabetes in America. 2nd ed. Washington, DC: Government Printing Office, 1995:429-48. (NIH publication No 95-1468.)

19 Moss SE, Klein R, Klein BEK, Meuer MS. The association of glycemia and cause-specific mortality in a diabetic population. Arch Intern Med 1994;154:2473-9.

20 Krolewski AS, Laffel LMB, Krolewski M, Quinn M, Warram JH. Glycosylated hemoglobin and the risk of microalbuminuria in patients with insulin-dependent diabetes mellitus. N Engl J Med 1995;332:1251-5.

21 Brownlee M. Glycation and diabetic complications. Diabetes 1994;43:83641.

22 Diabetes Control and Complications Trial Research Group. The effect of intensive treatment of diabetes on the development and progression of long-term complications in insulin-dependent diabetes mellitus. $N$ Engl Med 1993;329:977-86.

23 Diabetes Control and Complications Trial Research Group: The relationship of glycemic exposure $\left(\mathrm{HbA}_{1}\right)$ to the risk of development and progression of retinopathy in the diabetes control and complications trial. Diabetes 1995;44:968-83

24 Diabetes Control and Complications Trial Research Group: The absence of a glycemic threshold for the development of long term complications: the perspective of the diabetes control and complications trial. Diabetes 1996;45:1289-98.

25 UK Prospective Diabetes Study Group: Intensive blood glucose control with sulphonylureas or insulin compared with conventional treatment and risk of complications in patients with type 2 diabetes (UKPDS 33). Lancet 1998;352:837-53

26 Donahue RP, Abbott RD, Reed DM, Yano K. Post challenge glucose level and coronary heart disease in men of Japanese ancestry. Diabetes 1987;36:689-92.

27 Butler WJ, Ostrander LDJr, Carman WJ, Lamphiear DE. Mortality from coronary heart disease in the Tecumseh study: long-term effect of diabetes mellitus, glucose tolerance and other risk factors. Am J Epidemiol 1985; $121: 541-7$

28 Eschwege E, Richard JL, Thibult N, Ducimetiere P, Warner JM, Claude JR et al. Coronary heart disease mortality in relation with diabetes, blood glucose and plasma insulin concentrations. The Paris prospective study, ten years later. Horm Metab Res 1985;15(suppl series):41-5.

29 Pyorala K, Savolainen E, Kaukola S, Haapgoski J. Plasma insulin as a coronary heart disease risk factor: relationship to other risk factors and predictive value during 91/2 year follow up of the Helsinki policemen study population. Acta Med Scand 1985;(suppl)701:38-52.

30 Ohlson LO, Svardsudd K, Welin L, Eriksson H, Wilhelmsen L, Tibblin G, et al. Fasting blood glucose and risk of coronary heart disease, stroke, and all cause mortality: a 17 year follow up study of men born in 1913. Diabet Med 1986;3:33-7.

31 Fuller JH, Shipley MJ, Rose G, Jarrett RJ, Keen H. Coronary heart disease risk and impaired glucose tolerance. The Whitehall study. Lance 1980;:1373-6.

32 Scheidt-Nave C, Barrett-Connor E, Wingard DL, Cohn BA, Edelstein SL. Sex differences in fasting glycemia as a risk factor of ischemic heart disease death. Am J Epidemiol 1991:133:565-76.

33 Gerstein HC. Glucose: a continuous risk factor for cardiovascular disease. Diabet Med 1997;14:S25-31.

34 Coutinho M, Gerstein HC, Wang Y, Yusuf S. The relationship between glucose and incident cardiovascular events. Diabetes Care 1999;22:233-40.

35 Singer DE, Nathan DM, Keaven MA, Wilson PWF, Evans JC. Association of $\mathrm{HbA}_{1 \mathrm{c}}$ with prevalent cardiovascular disease in the original cohort of the Framingham Heart Study. Diabetes 1992;41:202-8. 
36 Vitelli LL, Shahar E, Heiss G, McGovern PG, Brancati FL, Eckfeldt JH, et al. Glycosylated hemoglobin level and carotid intimal-medial thickening in non-diabetic individuals. Diabetes Care 1997;20:1454-8.

37 Park S, Barrett-Connor E, Wingard DL, Shan J, Edelstein S. Ghb is a better predictor of cardiovascular disease than fasting or postchallenge plasma glucose in women without diabetes. The Rancho Bernardo study. Diabetes Care 1996;19:450-6.

38 De Vegt F, Dekker JM, Ruhe HG, Stehouwer CD, Nijpels G, Bouter LM, et al. Hyperglycaemia is associated with all-cause and cardiovascular mortality in the Hoorn population: the Hoorn Study. Diabetologia 1999;42:926-31.

39 Neaton JD, Wentworth D. Serum cholesterol, blood pressure, cigarette smoking and death from coronary heart disease. Overall findings and differences by age for 316099 white men. Multiple Risk Factor Intervention Trial Research Group. Arch Intern Med 1992;152:56-64

40 UK Prospective Diabetes Study (UKPDS) Group. Intensive blood glucose control with sulphonylureas or insulin compared with conventional treatment and risk of complications in patients with type 2 diabetes (UKPDS 33). Lancet 1998;352:837-53.

41 UK Prospective Diabetes Study Group. Tight blood pressure control and risk of macrovascular and microvascular complications in type 2 diabetes (UKPDS 38) BMJ 1998;317:703-13.

42 Wood DA, DE Backer G, Faergeman O, Graham J, Mancia G, Pyorala K. Prevention of coronary heart disease in clinical practice. Recommendations of the second joint task force of the European Society of Cardiology, European Atherosclerosis Society, and European Society of Hypertension. Eur Heart J 1998;19:1434-503.

43 British Cardiac Society, British Hyperlipidaemia Association, British Hypertension Society. Joint British recommendations on prevention of coronary heart disease in clinical practice. Heart 1998(suppl 2):S1-29.
44 DECODE Study Group, on behalf of the European Diabetes Epidemiology Group. Glucose tolerance and mortality: comparison of WHO and American Diabetes Association diagnostic criteria. Lancet 1999;354:61721.

45 Barzilay JI, Speikerman CF, Wahl PH, Kuller LH, Cushman M, Furberg $\mathrm{CD}$, et al. Cardiovascular disease in older adults with glucose disorders: comparison of American Diabetes Association criteria for diabetes mellitus with WHO criteria. Lancet 1999;354;622-5.

46 Shaw JE, Hodge Am, de Gurter M, Chitson P, Zimmet PZ. Isolated postchallenge hyperglycaemia confirmed as a risk factor for mortality. Diabetologia 1999;42:1050-4.

47 Hamman RF Genetic and environmental determinants of non-insulin dependent diabetes. Diabetes Metab Rev 1992;8:287-338.

48 Pan XR, Cao HB, Li GW, Hu YH, Wang JX, Yang WY, et al. Effects of diet and exercise in preventing NIDDM in people with impaired glucose tolerance. Diabetes Care 1997;20:537-44.

49 Rose G. Strategy of prevention: lessons from cardiovascular disease. $B M J$ 1981;282:1847-51.

50 Sargeant L, Wareham N, Bingham S, Day N, Luben R, Oakes S, et al. Vitamin $\mathrm{C}$ and glucose tolerance in a EPIC-Norfolk: a population study Diabetes Care 2000;23:726-32.

51 Williams DE, Wareham NE Cox BD, Byrne CD, Hales CN, Day NE. Frequent salad consumption is associated with a reduction in the risk of diabetes mellitus. J Clin Epidemiol 1999;52:329-35.

52 Wareham NJ, Wong MY, Day NE. Glucose intolerance and physical inactivity: the relative importance of low habitual energy expenditure and cardiorespiratory fitness. Am J Epidemiol 2000;152:132-9.

(Accepted 11 October 2000) 